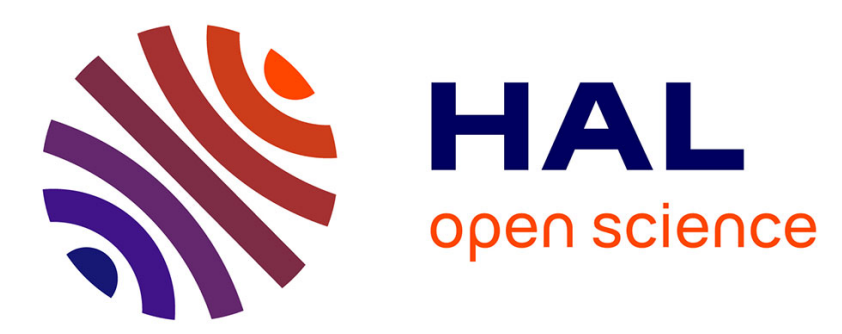

\title{
Multiconfiguration GPR measurements for geometric fracture characterization in limestone cliffs (Alps)
}

Mathieu Jeannin, Stéphane Garambois, Colette Grégoire, Denis Jongmans

\section{To cite this version:}

Mathieu Jeannin, Stéphane Garambois, Colette Grégoire, Denis Jongmans. Multiconfiguration GPR measurements for geometric fracture characterization in limestone cliffs (Alps). Geophysics, 2006, 71 (3), pp.B85-B92. 10.1190/1.2194526 . insu-00196696

\section{HAL Id: insu-00196696 https://hal-insu.archives-ouvertes.fr/insu-00196696}

Submitted on 13 Dec 2007

HAL is a multi-disciplinary open access archive for the deposit and dissemination of scientific research documents, whether they are published or not. The documents may come from teaching and research institutions in France or abroad, or from public or private research centers.
L'archive ouverte pluridisciplinaire HAL, est destinée au dépôt et à la diffusion de documents scientifiques de niveau recherche, publiés ou non, émanant des établissements d'enseignement et de recherche français ou étrangers, des laboratoires publics ou privés. 


\title{
MULTI-CONFIGURATION GPR MEASUREMENTS FOR GEOMETRICAL FRACTURE CHARACTERIZATION IN LIMESTONE CLIFFS (ALPS)
}

\author{
Mathieu Jeannin ${ }^{1}$, Stéphane Garambois ${ }^{1}$, Colette Grégoire ${ }^{2}$ \& Denis Jongmans ${ }^{1}$ \\ ${ }^{1}$ LIRIGM, Maison des Géosciences, Université Joseph Fourier, \\ BP 53, 38041 Grenoble Cedex 9, France. \\ 2 Department Civil Engineering, Katholieke Universiteit Leuven, \\ Kasteelpark Arenberg 40, B-3001 Heverlee, Belgium
}

\author{
Corresponding author: \\ Stéphane Garambois \\ Maison des Géosciences \\ LIRIGM - UJF \\ BP 53X, 38041 Grenoble Cedex 9, France \\ Tel : +33476828046 \\ e-mail : Stephane.Garambois@ujf-grenoble.fr
}




\begin{abstract}
Until now, geophysical methods have been rarely used to investigate vertical limestone cliffs, mainly due to the extreme conditions for data acquisition. Nevertheless, these techniques are the only available methods which could provide information on the internal state or a rock mass in terms of discontinuities, which play a major role in rock-fall hazards. In this case study, detailed GPR measurements were carried out on a test site with different acquisition configurations deployed on vertical cliff faces. Conventional 2D profiles, common midpoints (CMP) and transmission data were acquired to evaluate the potential of radar waves to improve the characterization of the geometry and properties of the main discontinuities (fractures) within the massif. The results show that the 3D geometry of fractures, which is a crucial parameter for stability assessment, can be retrieved by combining vertical and horizontal profiles performed along the cliff. CMP profiles acquired along the cliff allow a velocity profile to be obtained as a function of depth. Finally, transmission experiments, which generate complex radargrams, have provided valuable and quantitative information on the rock mass, through the modelling of the waves generated. On the other hand, a velocity tomography obtained from the first arrivals travelling through the rock mass from the transmitters to the receivers, shows an image of the investigated zone with a poor resolution.
\end{abstract}

\title{
INTRODUCTION
}

Among many natural hazards occurring in mountainous regions, rock falls are frequent phenomena characterized by their suddenness and their difficulty to predict. Growing urbanisation in such areas requires better assessment of the hazards linked to rock falls, and 
precise determination of the location and volume of a rock mass likely to fall. Rock mass stability assessment is a complex problem generally addressed from surface observations: slope morphology, mass fracturing, deformation measurements (Hoek and Bray, 1981; Rouiller et al., 1998). Even if such studies are essential, the lack of information concerning the geometry and properties of discontinuities within the rock mass leads to major uncertainty concerning hazard assessment. Besides drilling, only geophysical methods are able to obtain information about the discontinuity geometry within the massif studied. However, these techniques have rarely been applied to vertical cliffs or steep rock slopes, probably due to practical difficulties when carrying out geophysical experiments in such extreme conditions. At a lower scale and/or in easier field conditions, the GPR (Ground Penetrating Radar) method has been successfully applied to comparable geological problems such as fault and fracture 2D mapping in resistive rocks from surface acquisitions (Benson, 1995; Stevens et al., 1995; Demanet et al., 2001; Rashed et al., 2003) and in boreholes (Zhou and Sato, 2000). To image subhorizontal fractures as well as subvertical faults, Grasmueck (1996) developed a 3D radar technique, which was applied to a gneiss quarry. In a gypsum quarry, Dérobert and Abraham (2000) performed GPR profiles on pillars to characterize the crack depth and inclination, while damaged zones were imaged as low P-wave velocities by seismic tomography. Similarly, Toshioka et al. (1995) detected the distribution and continuity of cracks from GPR data acquired on the vertical wall of a welded tuff rock. Seol et al. (2001) developed a strike-direction-finding scheme using GPR data obtained from three different acquisition modes for the same survey line in a granite quarry. The computed reflector azimuths were found to be closely correlated to those of observed fractures and joints. In limestone formations, Pettinelli et al. (1996) and Pipan et al. (2003) showed, from 2D and 3D GPR measurements, that open fractures, joints or discontinuities filled with clay or water are clearly visible when an appropriate signal wavelength is used. In good quality rock, most of 
the radar wave energy is transmitted, while in low quality rock, the energy is backscattered from fractures, strata joints and cavities. Using this property, Orlando (2003) defined a semiquantitative evaluation method based on the amount of backscattered energy as an index of rock quality. In a more quantitative way, Grégoire et al. (2003) studied the GPR reflection coefficient of fractures in the frequency domain and deduced the aperture and the filling material of fractures from multi-frequency reflection data, when a reference signal is known.

Recently, Dussauge-Peisser et al. (2003) carried out GPR measurements and seismic tomography on a $12 \mathrm{~m}$ high limestone cliff with GPR antennae and some geophones set on the cliff. Their results indicate that simple vertical GPR profiles performed on the cliff were efficient to detect and image subvertical discontinuities as far as $10 \mathrm{~m}$ in depth, which were closely correlated with fractures deduced from surface observations. In contrast, seismic tomography, performed with sources and geophones deployed on the surface and on the cliff, was incapable of detecting and characterizing individual fractures, but provided a low resolution image of rock mass stability. In a similar way, Cardarelli et al. (2003) used both GPR and seismic data for tunnel stability assessment. Radar data supplied information about the number and location of discontinuities in the investigated zone, while seismic methods provided estimates of the distribution of the mean elastic properties.

Compared to previous studies, this paper takes a step forward in the use of multiconfiguration GPR experiments applied to the subalpine massifs near Grenoble (France). Conventional 2D profiles, common midpoints (CMP) and transmission data were acquired to evaluate the potential of characterizing the geometry and properties of the fracture network and stability of vertical cliffs.

To assist interpretation, transmission data were modelled using a 2D full-waveform modelling code and the first arrival time picks were inverted for both real and synthetic data. Indeed, seismic and GPR tomography have been widely used to investigate rock masses (e.g. Ivanson, 
1987; Hollender, 1999; Demanet, 2000; Jongmans et al., 2000). Although crosshole transmission tomography is the most widespread method (Ivanson, 1987; Bois et al., 1972; Corin et al., 1997), surface tomography (all sources and receivers located at the ground surface) is increasingly used, to avoid expensive drilling costs or destructive investigations (Liu et al., 1998; Lanz et al., 1998). Radar tomography can also be used to study attenuation (Hollender, 1999), diffraction or dispersion (Olhoeft, 1993). In this study, we applied radar tomography to map the velocity distribution inside the investigated zone.

GPR measurements were conducted using a RAMAC/GPR system (MALÁ Geosciences), which was adapted to such extreme conditions. Indeed, as the main fracture networks are almost vertical, only profiles where at least one antenna was directly positioned on the cliff surface were able to image the possible interfaces created by these discontinuities. For this reason, and to optimize the coupling between the rock surface and the antennas, an operator had to climb down the cliff with the antennae and suitable cables. All profiles were acquired with unshielded antennas and using the TE (Transverse Electric) mode.

In this paper, GPR measurements were carried out on a calcareous cliff (Fig. 1A). This site does not present any specific rock fall hazard and was chosen mainly for its accessibility and for the simplicity of its geological structure.

\section{DESCRIPTION OF THE TEST SITE}

Calcareous cliffs surrounding the urban area of Grenoble city (Isère, France) extend over a cumulative length of $120 \mathrm{~km}$ (Fig. 1A) and can be up to $400 \mathrm{~m}$ high (Fig. 1B). They are part of the Chartreuse and Vercors subalpine massifs made of sedimentary rocks of upper Jurassic and lower Cretaceous age (limestone and marls). Most of the cliffs are located in Tithonian 
and Urgonian limestone beds which dip slightly cliffwards (Fig. 1B). Because of the cliff morphology, this region has been subject to extensive rock fall risk (ranging from block fall to major events), which has been studied using a probabilistic approach (Dussauge-Peisser et al., 2002). During the $13^{\text {th }}$ century, the Chartreuse massif experienced a major rock fall with an estimated volume of 500 million cubic meters and a transport distance of 7.5 kilometres from the cliff (Goguel and Pachoud, 1972).

The test site is a $12 \mathrm{~m}$ high cliff made of Tithonian limestone (Upper Jurassic) which forms a subhorizontal plateau covered by organic soil. Detailed structural studies, carried out from surface observations on the cliff and on the plateau, showed that the rock mass is affected by three main discontinuity sets (Fig. 2): the bedding planes (labelled So) dipping gently inside the massif $\left(\mathrm{N} 30^{\circ} \mathrm{E} / 20^{\circ} \mathrm{NW}\right)$ and two vertical fracture sets $\left(\mathrm{N} 140^{\circ} \mathrm{E} / 90^{\circ}\right.$ and $\mathrm{N} 30^{\circ} \mathrm{E} / 90^{\circ}$, Fig. 2C). The first fracture set is predominant and clearly visible on the entire cliff. Open fractures are filled with a mix of clay and organic soil. The surface location of the observed fractures is displayed in figure $2 \mathrm{~B}$ (labelled $\mathrm{F} 1$ to $\mathrm{F} 5$ ) along an $\mathrm{AB}$ axis perpendicular to the fracture strike (Fig. 2A). The secondary fracture set, oriented $\mathrm{N} 30^{\circ} \mathrm{E}$, is mainly visible in the western part of the site (Fig. 2A) and is locally exposed on the cliff face. Due to the presence of organic cover above the limestone cliff (on the horizontal plateau), the extension of the different fracture sets inside the rock mass cannot be determined from surface observations.

In order to evaluate the potential of GPR data to detect the $2 \mathrm{D} / 3 \mathrm{D}$ geometry of the fracture sets, different GPR acquisition patterns were carried out. Due to the attenuating organic soil on top of the cliff and the sub vertical orientation of the main fractures, all measurement configurations had at least one antenna placed directly on the cliff. Figure 3 displays the design of a typical vertical profile acquisition in TE mode. We performed vertical and horizontal 2D profiles, Common Mid Point (CMP) and transmission experiments between the vertical cliff and the plateau. 


\section{PROFILES ALONG THE CLIFF, VERTICAL AZIMUTH}

The reflection mode configuration is the most common for subsurface measurements. In our study, GPR data were acquired along vertical profiles with antennae placed directly on the cliff. The $1 \mathrm{~m}$ long transmitter-receiver pair was moved in increments of $20 \mathrm{~cm}$. Figure 4 shows an example of raw (A) and processed (B) data acquired using $100 \mathrm{MHz}$ unshielded antennas along the vertical cliff as a function of time. The main events identified from the raw data are the direct air wave (between 3 and $20 \mathrm{ns)} \mathrm{and} \mathrm{reflected} \mathrm{events} \mathrm{to} 75$ ns two-way travel-time which present high reflectivity variations as a function of vertical location. To increase the amplitude of late (deep) events, the data were processed and filtered. First, a [10200] MHz band-pass zero-phase Butterworth filter was applied, followed by a top-mute of direct air-wave arrival and notch filters designed to attenuate multiple monofrequency reverberations (ringing). Then, an automatic gain control (AGC) was applied, which enhanced the late arrivals but led to the loss of the real amplitude information. The processed radargram (Fig. 4B) shows several reflected signals to $280 \mathrm{~ns}$ (two-way traveltime).

\section{VERTICAL AZIMUTH CMP PROFILE}

To obtain a velocity profile as a function of distance behind the cliff face, a Common MidPoint Profile (CMP) was performed by varying the radar antenna spacing across a central location at $5 \mathrm{~m}$ from the top of the cliff. Two operators carrying one antenna each had to go up and down the cliff from this central location. $200 \mathrm{MHz}$ antennas were chosen to reach a 
compromise between depth penetration and resolution. The CMP section (Fig. 5A) was filtered using a [30-300] $\mathrm{MHz}$ band-pass Butterworth filter and amplitudes were equalized with AGC. The Normal Moveout (NMO) was analyzed using the semblance maxima approach (Yilmaz, 1987), which is commonly used in seismic processing and yields the stacking velocity (Fig. 5B). Five reflected events were picked on the combined semblance and CMP gather panels (Fig. 5B). Four of them (F1, F2-F3, F4 \& F5) will be shown to correspond to the location of the observed fractures (Fig. 6). Only the onset of the main reflected waves was picked because of the difficulty to identify reflections from closely spaced reflectors, as for example for the reflected waves occurring at 55 ns two-way travel-time. The corresponding interpretation (reflections at fractures F2 and F3) was made possible considering figure $6 \mathrm{C}$, which shows that fracture $\mathrm{F} 2$ dips within the rock-mass toward fracture F3. Considering the CMP interpretations, it is noticeable that the F6 fracture was not noticed from surface observations. A deeper reflected wave can be distinguished around $230 \mathrm{~ns}$, but only for low offsets, preventing any hyperbola fitting. Figure 5C displays the data after NMO corrections computed using the velocity presented on figure 5B. Almost all reflected events have been correctly flattened, indicating that the NMO velocity profile is well-constrained.

The average interval velocities $V_{i, j}$ between times $t_{i}$ and $t_{j}$, were computed from the NMO velocity using the Dix formula (Dix, 1955). Although this process may suffer from numerical problems when reflections are closely spaced or when RMS velocities vary rapidly (Clapp, 2001), it allows the interval velocities to be approximately derived. The obtained velocity profile (Fig. 5D) shows moderate 1D velocity variations inside the rock mass. It presents a slight velocity increase from $10.5 \mathrm{~cm} / \mathrm{s}$ at the surface to $12 \mathrm{~cm} / \mathrm{s}$ at $1.9 \mathrm{~m}$ deep. This value characterises the sound limestone. Below $3 \mathrm{~m}$, the velocity decreases, reaching $8 \mathrm{~cm} / \mathrm{s}$ between 5.4 and $7.6 \mathrm{~m}$ deep. This velocity reduction is probably linked to the growing 
influence of the clayey filling of the main fractures F2 to F5. Beyond $7.6 \mathrm{~m}$, the velocity increases up to $10 \mathrm{~cm} / \mathrm{s}$.

Figure 5E presents the stack of NMO corrected data (Fig. 5C), which amplified the reflections and allowed a correlation of the reflected events with the observed fractures.

\section{VERTICAL AZIMUTH RADAR PROFILE RECORDED AT DIFFERENT FREQUENCIES}

Four different antennas with centre frequency of 50,100, 200 and $400 \mathrm{MHz}$ were used along a same profile on the cliff with a vertical azimuth and a trace spacing of $20 \mathrm{~cm}$. The four radargrams shown in figure 6 were filtered and processed in the same way as in the example presented in figure 4, except for the band-pass filter which was adapted to the centre frequency of each antenna. In addition, the radar sections were migrated considering the velocity profile deduced from the CMP analysis (Fig. 5D). On each GPR section we can see numerous vertical reflectors which are almost parallel to the cliff wall (except F2, which dips toward the rock mass). Most of them correspond to the main fractures observed from the surface (F1, F2, F3, F4 \& F5, Fig. 2B), which are located at 0.9, 2, 3.2, 5.5 and 9 meters from the profile along the cliff (Fig. 2B). These fractures are well correlated with reflected events both in the CMP data and in the profile with a vertical azimuth. Two deeper fractures (F6 \& F7) were detected with these measurements, which were probably masked by the organic cover located on the horizontal plateau. Fracture F6 already appeared on the CMP measurements (Fig. 5A).

The four radar sections show information about these fractures, with the classical trade-off between resolution and penetration depth. Some shallow reflectors (F1 \& F2) are only 
observed with the higher frequency antennas while deeper events (F6 \& F7) are imaged using lower frequency antennas. No multiple reflected wave was identified. The penetration depth of the radar waves ranges between $21 \mathrm{~m}$ with the $50 \mathrm{MHz}$ antenna and $10 \mathrm{~m}$ with the 400 MHz. The 100 and $200 \mathrm{MHz}$ radar sections appear to be the best compromise between resolution and penetration. Indeed, due to its lack of resolution, the $50 \mathrm{MHz}$ radargram is difficult to use in order to position accurately the discontinuities.

Reflectivity variations versus position are clearly visible along the same reflector (for example for the fracture F3), as well as a function of frequency. Indeed, in a given frequency range, the fracture detection with GPR depends on the thickness and filling material of the discontinuities. These dispersive properties can be modelled using the Jonscher formulation (Jonscher, 1977), and already showed their efficiency in retrieving fracture opening in a salt mine (Grégoire et al., 2003), considering thin layer approximation.

\section{D ACQUISITION TOWARD 3D}

For a better characterization of the spatial fracture geometry, we recorded a horizontal azimuth GPR profile on the cliff wall using $200 \mathrm{MHz}$ antennae with a trace spacing of $20 \mathrm{~cm}$. The horizontal profile, which was $13 \mathrm{~m}$ long and located at $5 \mathrm{~m}$ from the top of the cliff, required two people to abseil. The raw data were filtered and migrated in the same manner as the other 2D profiles. Figure 7 shows a pseudo 3D view of the $200 \mathrm{MHz}$ vertical and horizontal profiles. Compared to the single vertical profile, the combination of the two profiles allows the definition of potentially unstable volumes for rock stability assessment. In this example, two sets of reflectors are clearly visible. Knowing the cliff wall direction $\left(\mathrm{N} 100^{\circ} \mathrm{E}\right)$, the azimuths of the two sets of fractures can be deduced from the GPR data, which 
correspond to the orientations observed in the outcrop. On the two profiles, each reflected wave exhibits reflectivity variations, suggesting that the fracture properties (aperture, filling) may vary in space.

\section{TRANSMISSION EXPERIMENT}

The potential of GPR velocity tomography in characterizing discontinuities within the rockmass was tested with $100 \mathrm{MHz}$ antennas in transmission mode.

The GPR antenna configuration and the preliminary location of the fractures are shown on figure $8 \mathrm{~A}$. The transmitting antenna was moved vertically every $1 \mathrm{~m}$ along the cliff surface (transmitters $\mathrm{T} 1$ to $\mathrm{T} 11$ ). For each transmitter position, the receiving antenna was displaced along the plateau at $1 \mathrm{~m}$ intervals (receivers $\mathrm{R} 1$ to $\mathrm{R} 20$ ) along a profile which is roughly orthogonal to the cliff (Fig. 2A). According to the structural study, fractures F1 to F5 cross the profile on the plateau near receivers R1, R3, R5, R11 and R16, respectively. Figure 8B displays a typical radar section for the transmitting antenna T7. A finite differences numerical modelling code (GPRMAX2D, Giannopoulos, 2002) was used to identify the different waves, by comparing synthetic and real data. The modelled media are characterized by linear and isotropic properties, i.e., conductivity and the relative dielectric permittivity described using the Debye formulation. Figure 9A displays the model geometry with a limestone velocity of $11 \mathrm{~cm} / \mathrm{ns}$, the three main vertical fractures deduced from the $100 \mathrm{MHz}$ vertical azimuth profile (Fig. 6B), which are characterized by a clay velocity of $7.5 \mathrm{~cm} / \mathrm{ns}$, and the upper soil with a velocity of $7.5 \mathrm{~cm} / \mathrm{ns}$. The fracture apertures, which are unknown at that depth, were defined from trial-and-error tests. The synthetic radargram for transmitter $\mathrm{T} 7$ is presented on figure 9B. On both real and synthetic data (Fig. 8B \& 9B), five types of waves can be identified (see figure captions). The systematic delay of a few ns between the synthetic signals and the real 
one is a consequence of not including fracture F1. The wave transmitted in the rock mass (labelled 3 in figures 8 and 9) locally exhibits time delays, observed at receivers R6, R12 and $\mathrm{R} 15$ on the real data, and at receivers R4, R7 and R13 on the synthetics. These delays are due to the crossing of low velocity zones which also generate reflected events (labelled 5). These low velocity zones are correlated with fractures F2, F3, F4 and F5 (Fig. 8A) indicating that fractures are probably filled with clay material (or organic soil), as already shown by the CMP analysis (Fig. 5) showing a velocity decrease.

Thanks to the 2D modelling, the direct waves transmitted in the ground were successfully identified and used to obtain a velocity tomography of the rock mass. For this, first break arrival times were picked on all radargrams and inverted using the Simultaneous Iterative Reconstruction Technique (Dines and Lyttle, 1979), which was implemented in a 3D software for seismic velocity tomography analysis (Demanet, 2000). The velocity of the homogeneous starting model was $12 \mathrm{~cm} / \mathrm{ns}$. Demanet (2000) showed that the final velocity distribution has a low sensitivity towards the starting model, except in problematic situations where a priori information is necessary to avoid non-uniqueness. In order to evaluate the efficiency of the tomography method, the transmitted waves generated from the synthetic model described in figure 9A were also analysed using the same layout. Figure 10 shows the computed 2D real (a) and synthetic (b) velocity tomographies, which were obtained after 9 iterations. In the same figure are displayed the RMS evolution with the number of iterations and the raypaths. The resulting images appear both smoothed and exhibit similar features: a low velocity zone near the surface, related to the soil cover, a smooth velocity decrease at the fracture locations (F3 \& F4 for the real case) with limited vertical extension, as well as a $3 \mathrm{~m}$ thick homogeneous zone presenting a velocity of around $11.5 \mathrm{~cm} / \mathrm{ns}$ close to the cliff. All these features correlate well with the velocity analysis deduced from the CMP data and justify afterwards the model used for the simulation (fig 9A). However, due to the image smoothness 
and the huge effort required, the transmission technique appears to be of little interest for accurately detecting and characterizing the fracture network.

\section{CONCLUSIONS}

GPR measurements with different layouts were performed on a limestone cliff, with the aim of imaging the discontinuities inside the rock mass. As the plateau is covered with a conductive weathered layer and the two main sets of fractures are near vertical, GPR reflection profiles were carried out on the vertical cliff face. In the geological context of these Mesozoic limestone massifs, a maximum penetration of $20 \mathrm{~m}$ was reached with $100 \mathrm{MHz}$ antenna which gave a satisfactory resolution. Although this work required a complex data acquisition effort, particularly for the horizontal azimuth profile, the results showed the presence of several reflectors, the location and orientation of which coincide with the fractures observed at the surface. The additional and very valuable information brought by GPR measurements is the imaging of the fracture network with a resolution of a few $\mathrm{cm}$ for the high frequency antenna. At the present time, such high quality GPR measurements are probably the only technique allowing a detailed investigation of the rock mass inside. Its application in rock fall assessment could be of great interest for defining potential unstable blocks. Due to the relatively low penetration depth, the technique is however limited to volumes of about a few tens to hundreds of $\mathrm{m}^{3}$. The cost of the experiments will probably restrict the use of the technique to cases where the risk is high. For applications, improvements have to be made to the acquisition system. Wireless technology should be developed in order to move the instrument efficiently on the cliff. When possible, GPR data 
should be coupled with laser scanning techniques to position the GPR traces on a numerical model of the cliff and to define the 3D geometry of the potentially unstable blocks. All the data acquired during this study exhibit reflectivity variations both with distance along a same fracture and with frequency, which suggest that GPR measurements are sensitive to fracture properties (filling, aperture). In the future, the reflection coefficient versus frequency should be inverted to characterize the fractures, as proposed by Gregoire et al. (2003). The main difficulty to overcome at the present time is to compute the reflection coefficient which depends on the source signal likely to vary from one trace to the other. APVO (Amplitude and Phase versus Offset) curves derived from CMP data acquired both in TE and TM modes should also help characterization, as well as polarization studies (Tsoflias et al., 2004).

\section{ACKNOWLEDGMENTS}

All data were processed using Seismic Unix. The authors acknowledge the contribution from

Dr. A Giannopoulos who made the 2D modelling code available to everyone (GprMax2D can be downloaded from the address: http:/www.see.ed.ac.uk/ agianno/GprMax/). This work was partially supported by the "Pole Grenoblois des Risques Naturels" through a funding from the Conseil General de l'Isère (France) and by the Parc Régional de Chartreuse. We thank everyone who helped us during the field experiments and particularly Michel Sintès for providing us with topographic data.

\section{REFERENCES}


Benson A.K., 1995, Application of ground penetrating radar in assessing some geological hazards: examples of ground water contamination, faults, cavities, Journal of Applied Geophysics, 33, 177-193.

Bois P., la Porte M., Lavergne M. and Tomas G., 1972, Well-to-well seismic measurements, Geophysics, 37, 471-480.

Cardarelli E., Marrone C. and Orlando L., 2003, Evaluation of tunnel stability using integrated geophysical methods, Journal of Applied Geophysics, 52, 93-102.

Clapp, R. G., 2001, Geologically constrained migration velocity analysis, Ph.D. thesis, Stanford University.

Corin L., Couchart I., Dethy B., Halleux L., Monjoie A., Richter T., and Wauters J.P., 1997. Radar tomography applied to foundation design in a karstic environment, Modern Geophysics and Engineering Geology, 19, 167-173.

Demanet D. 2000. Tomographie 2D et 3D a partir de measures geophysiques en surface et en forage. PhD thesis, University of Liege.

Demanet D., Renardy F., Vanneste K., Jongmans D., Camelbeek T. and Meghraoui M., 2001. The use of geophysical prospecting for imaging active fault in the Roer Graben, Belgium. Geophysics, 66, pp. 78-89. 
Dines K. and Lyttle J., 1979. Computerized geophysical tomography. In: IEEE, pp. 10651073.

Dérobert X. and Abraham O., 2000, GPR and seismic imaging in a gypsum quarry, Journal of Applied Geophysics, 45, 157-169.

Dix C.H., 1955, Seismic velocities from surface measurements, Geophysics, 20, 68-86.

Dussauge-Pesser C., Helmstetter A., Grasso J.-R., Hantz D., Jeannin M. And A. Giraud, 2002, Probabilistic approach to rock fall hazard assessment: potential of historical analysis, Natural Hazards and Earth System Sciences, 2, 1-13.

Dussauge-Pesser C., Wathelet M., Jongmans D., Hantz D., Couturier B. and Sintes M., 2003, Investigation of a fractured limestone cliff (Chartreuse Massif, France) using seismic tomography and ground penetrating radar, Near Surface Geophysics, 1, 161-170.

Giannopoulos A., 2002, GPRMAX2D/3D User's guide, http://www.gprmax.org.

Goguel J. and Pachoud A., 1972, Géologie et dynamique de l'écroulement du Mont Granier, dans le massif de la Chartreuse, en novembre 1248, Bulletin du B.R.G.M., III(1), pp. 29-38.

Grasmueck M., 1996, 3-D ground penetrating radar applied to fracture imaging in gneiss, Geophysics, 61, 1050-1064. 
Grégoire C., Halleux L. and Lukas V., 2003. GPR capabilities for the detection and characterisation of open fractures in a salt mine, Near Surface Geophysics, 1, p. 139-147.

Hoek E. and Bray J. W., 1981, Rock slope engineering, Elsevier Science, Cambridge.

Hollender F.,1999. Interprétation de la distorsion des signaux géoradar propagés et réfléchis Développement d'une tomographie par bandes de fréquences. PhD thesis, INPG.

Ivanson S., 1987. Crosshole transmission tomography. In: Seismic tomography with applications in global seismology and exploration geophysics (ed. G. Nolet), pp. 159-188. Reidel Publishing Company.

Jongmans D., Hemroulle P., Demanet D., Renardy F., and Vanbrabant Y., 2000. Application of 2D electrical and seismic tomography technics for investigating landslides. Eur. J. Env. Eng. Geophysics, 5, pp. 75-89.

Lanz E., Maurer H. and Green A. G., 1998. Refraction tomography over a buried waste disposal site. Geophysics 63(4), 1414-1433.

Liu L., Lane J. W., Quan Y., 1998. Radar attenuation tomography using the centroid frequency downshift method, Journal of Applied Geophysics, 40, 108-116.

Olhoeft G. R., 1993. Velocity, attenuation, dispersion and diffraction hole-to-hole radar, $4^{\text {th }}$ Tunnel Detection Symposium on Subsurface Technology, Proceedings, 26-29. 
Orlando L., 2003, Semiquantitative evaluation of massive rock quality using ground penetrating radar, Journal of Applied Geophysics, 52, 1-9.

Pettinelli E., Beaubien S., and Tommasi P., 1996, GPR investigation to evaluate the geometry of rock slides and buckling in a limestone formation in northern Italy, European Journal of Environmental and Engineering Geophysics, 1, 271-286.

Pipan M., Forte E., Guangyou F. \& I. Finetti, 2003, High-resolution GPR imaging and joint characterisation in limestones, Near Surface Geophysics, 1, 39-55.

Rashed M., Kawamura D., Nemoto H., Miyata T. and Nakagawa K., 2003, Ground penetrating radar investigations across the Uemachi fault, Osaka, Japan, Journal of Applied Geophysics, 53, 63-75.

Rouiller J. D., Jaboyedoff M., Marro C., Philippossian F. and Mamin M., 1998, Pentes instables dans le Pennique valaisan. MATTEROCK: une méthodologie d'auscultation des falaises et de détection des éboulements majeurs potentiels. Final Report PNR31, VDF, Zürich.

Seol S.Y., Kim J.-H., Song Y., and Chung S.-H., 2001, Finding the strike direction of fractures using GPR, Geophysical Prospecting, 49, 300-308. 
Stevens K.M., Lodha G.S., Holloway A.L., and Soonawala N.M., 1995, The application of ground penetrating radar for mapping fractures in plutonic rocks within the Whiteshell Research Area, Pinawa, Manitoba, Canada., Journal of Applied Geophysics, 33, 125-141.

Toshioka T., Tsuchida T., and Sasahara K., 1995, Application of GPR to detect and mapping cracks in rock slopes, Journal of Applied Geophysics, 33, 119-124.

Tsoflias G.P., Van Gestel J.-P., Stoffa P.L., Blankenship D.D., and Sen M., 2004, Vertical fracture detection by exploiting the polarization properties of ground-penetrating radar signals, Geophysics, 69, 803-810.

Yilmaz, O., 1987, Seismic data processing, Society of Exploration Geophysics, Tulsa.

Zhou , H. and M. Sato, 2000, Application of vertical radar profiling technique to Sendai castle, Geophysics, 65, 533-539. 


\section{FIGURE CAPTIONS}

Fig. 1: (A) Geological map of the city of Grenoble (France), and location of the studied site in the Chartreuse massif.(B) Typical geological cross-section of the limestone cliffs surrounding the city of Grenoble.

Fig. 2: Schematic representation of the test site (Chartreuse massif). (A) location of the main fractures (F1 to F5) deduced from structural observations and different GPR tested configurations. Direction AB is orthogonal to the fracture strike direction. (B) Hypothetical view of the fractures along the $\mathrm{AB}$ profile. (C) Stereogram of the observed fractures showing two main networks.

Fig. 3: Photography of GPR data acquisition on a vertical cliff face (TE mode).

Fig. 4: An example of a vertical GPR profile acquired along the cliff with $100 \mathrm{MHz}$ antennas. (A) time raw data. (B) processed data.

Fig. 5: (A) Filtered CMP data. The record shows a top direct air wave arrival with a velocity of $30 \mathrm{~cm} / \mathrm{ns}$, a poor signal to noise ratio linear wave arrival propagating directly in the limestone, as well a several reflected waves and their corresponding hyperbolae picking. The hyperbolae are labelled considering their fracture correspondence. (B) Semblance analysis of reflected events and deduced NMO velocity profile as a function of time. (C) CMP data after 
NMO corrections. (D) Interval velocity profile deduced from the NMO velocity profile using the Dix formula. (E) GPR trace after NMO corrections and stack of CMP data.

Fig. 6: Comparison of identical GPR vertical azimuth profile acquired with different antenna frequencies. (A) $50 \mathrm{MHz}$, (B) $100 \mathrm{MHz}$, (C) $200 \mathrm{MHz}$ and (D) $400 \mathrm{MHz}$. All GPR sections were filtered and migrated using the velocity profile presented in Fig. 5. The main fractures (observed from structural surface investigations or deduced from GPR data) are denoted F1 to F7.

Fig. 7: Combination of vertical and horizontal $200 \mathrm{MHz}$ profiles, showing the orientation and dipping of the main discontinuities. The data were filtered and migrated.

Fig. 8: Transmission experiment. (A) layout of the field experiment and location of the main observed fractures (F1 to F5). (B) Real transmission radargram obtained for transmitter T7 and main EM events labelled 1 to 5. They correspond to (1) the direct air wave, (2) the ground wave, (3) a diffracted wave at the corner of the cliff, (4) the transmitted wave inside the rock mass and (5) reflected waves on fractures. This interpretation was possible thanks to synthetic data and associated raypaths showed on Fig. 9.

Fig. 9: (A) Geological model used in the GPR transmission modelling and raypaths associated with each identified event. (B) Synthetic transmission radargram obtained for transmitter T7 from the geological model showed in (A). The direct air wave ("1", in blue) presenting a 30 $\mathrm{cm} / \mathrm{ns}$ velocity is followed by the ground wave ("2", in yellow) propagating from the transmitter to each receiver, and which exhibits an apparent velocity of $10.5 \mathrm{~cm} / \mathrm{ns}$ (it propagates in a conductive medium, thus explaining its low amplitude). The third wave (“3”, 
in red) also presents a $30 \mathrm{~cm} / \mathrm{ns}$ velocity, but arrives with a $40 \mathrm{~ns}$ delay on the plateau. This wave propagates in limestone along the surface of the cliff wall, and is diffracted in the air at the corner of the cliff. Finally, we can observe the direct ground wave ("4", in green), transmitted inside the rock mass and reflected waves ("5", in black) on the fractures, which can be used for imaging.

Fig. 10: Real (A) and synthetic (B) GPR tomographies of the investigated rock mass. The raypaths indicate the spatial resolution of this image. The decreasing of the RMS error as a function of the number of iterations is displayed. 


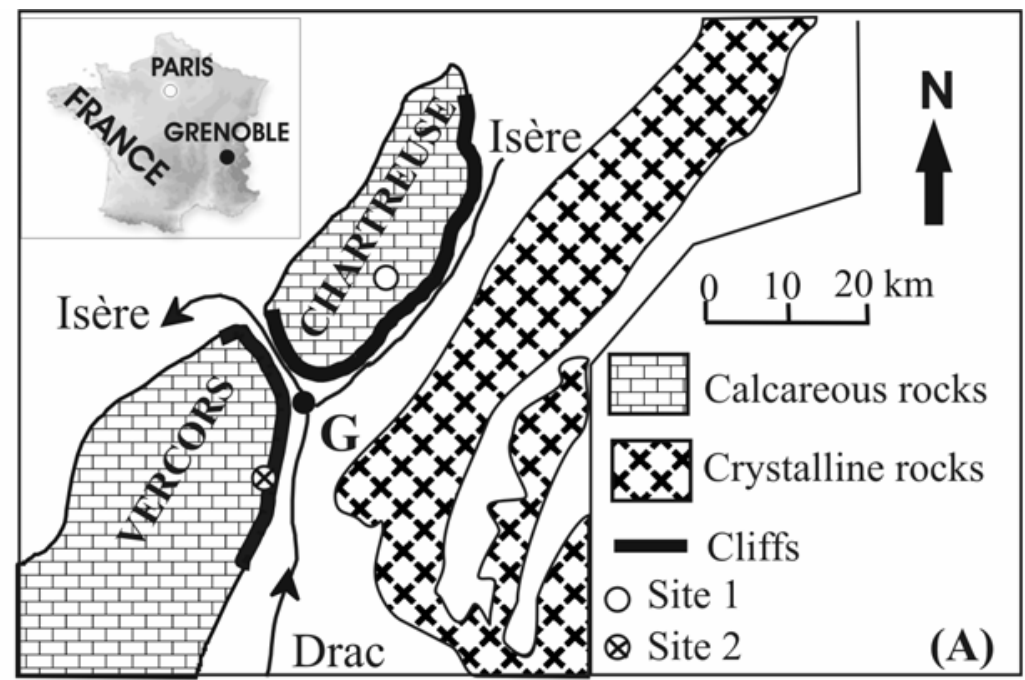

NW

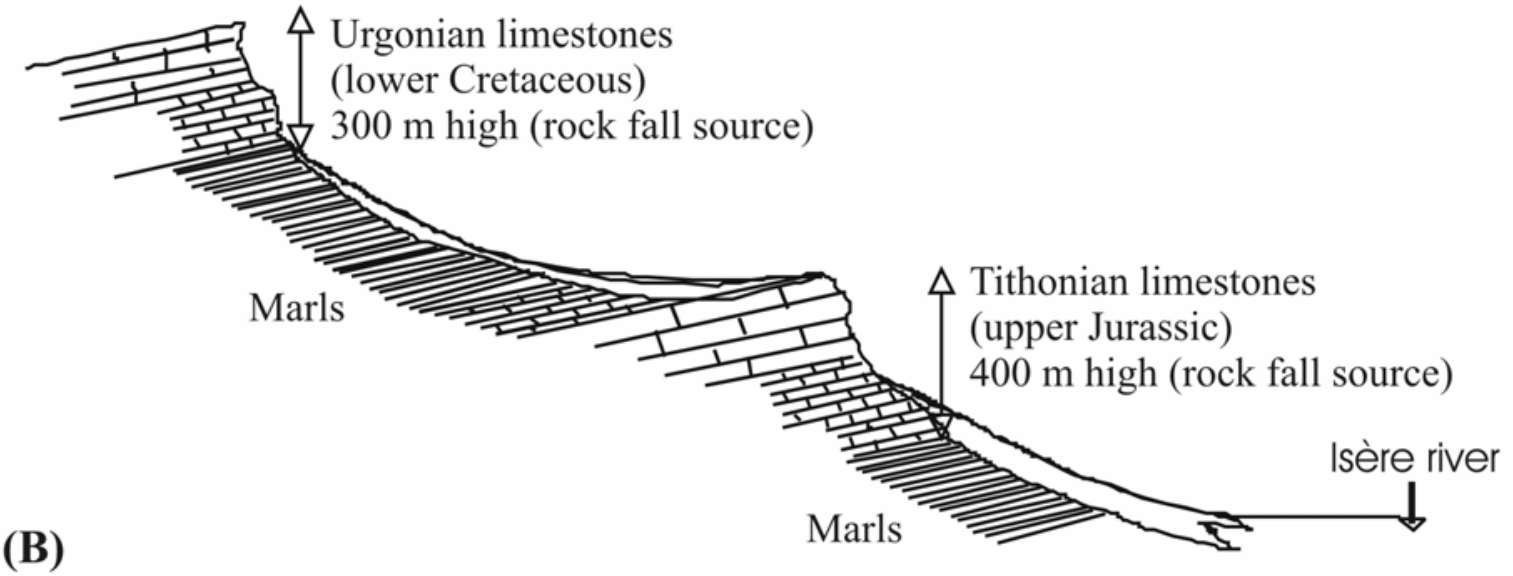

Figure 1 

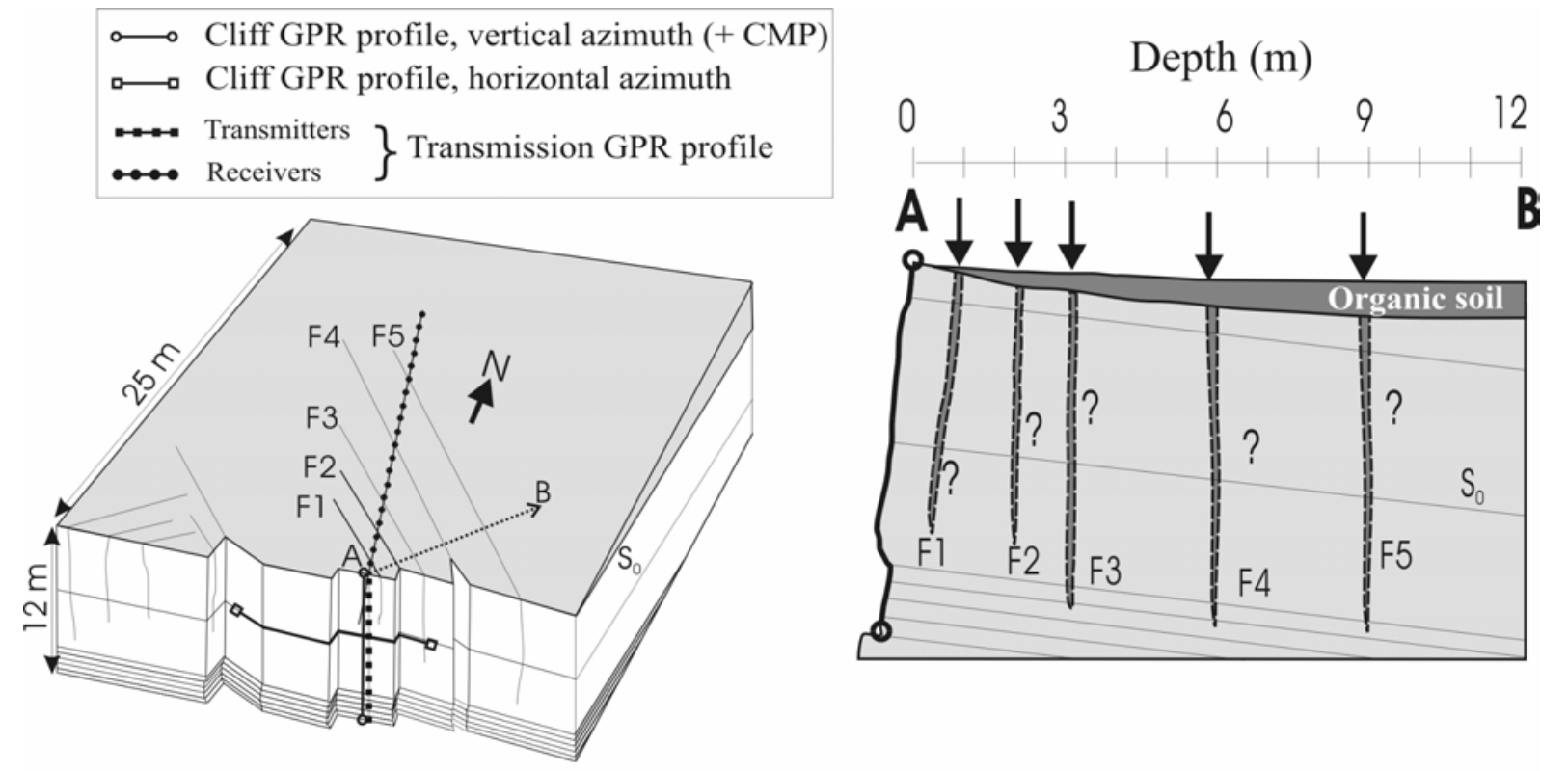

(A)

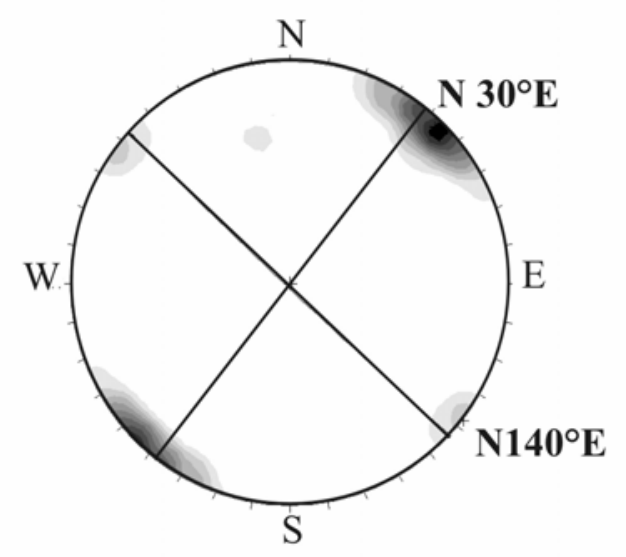

(B)

(C)

Figure 2 


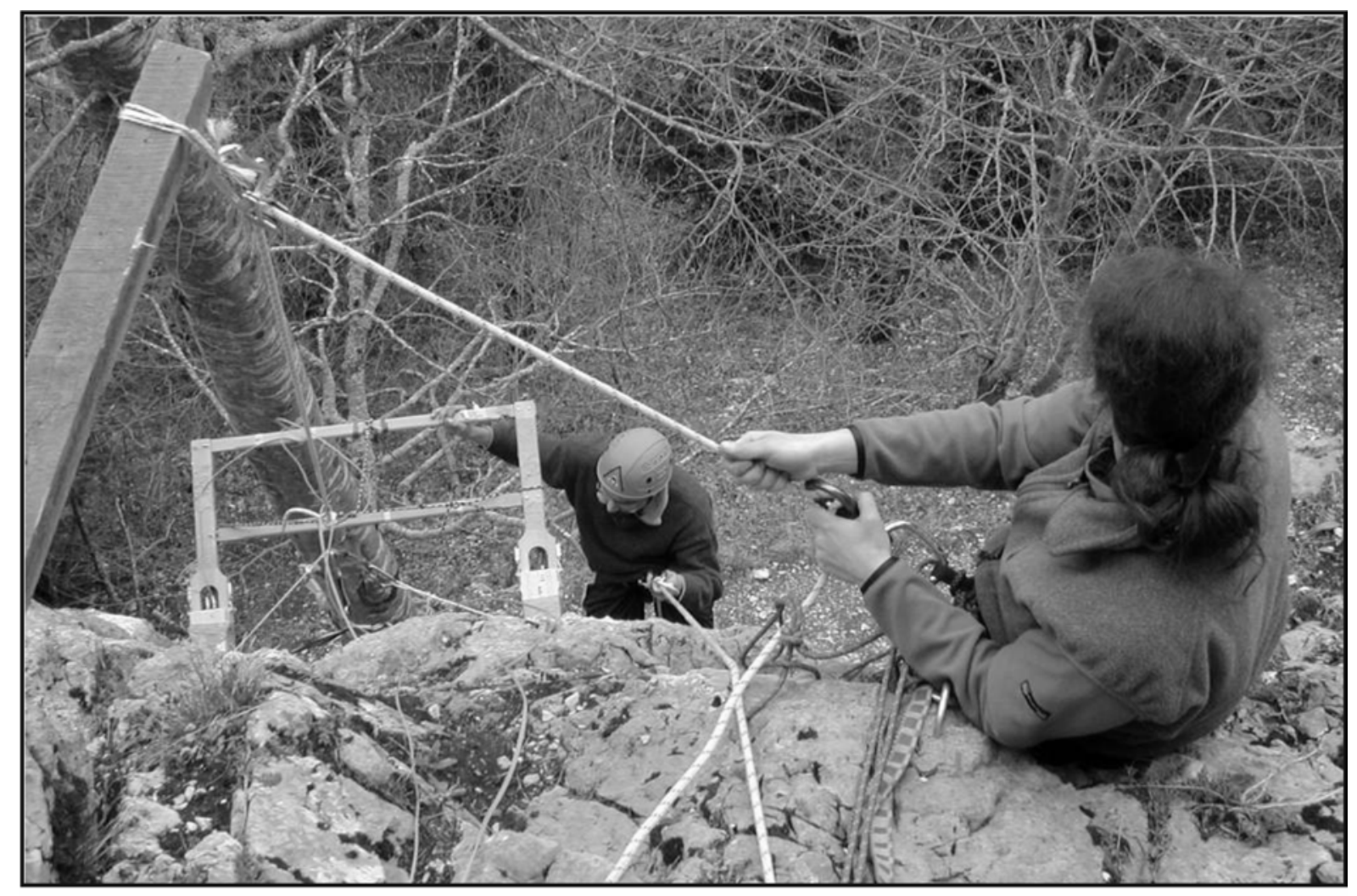

Figure 3 

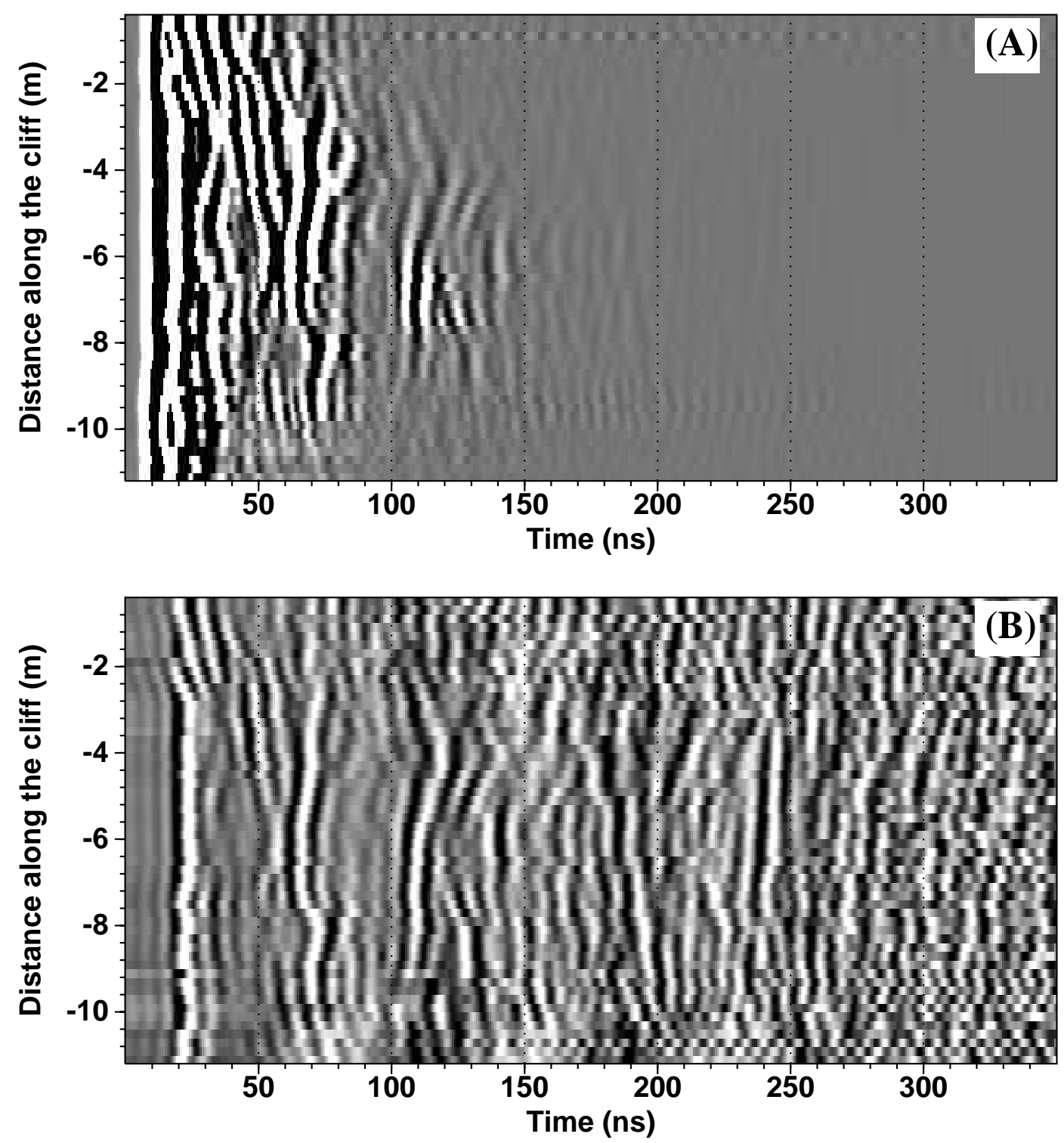

Figure 4 

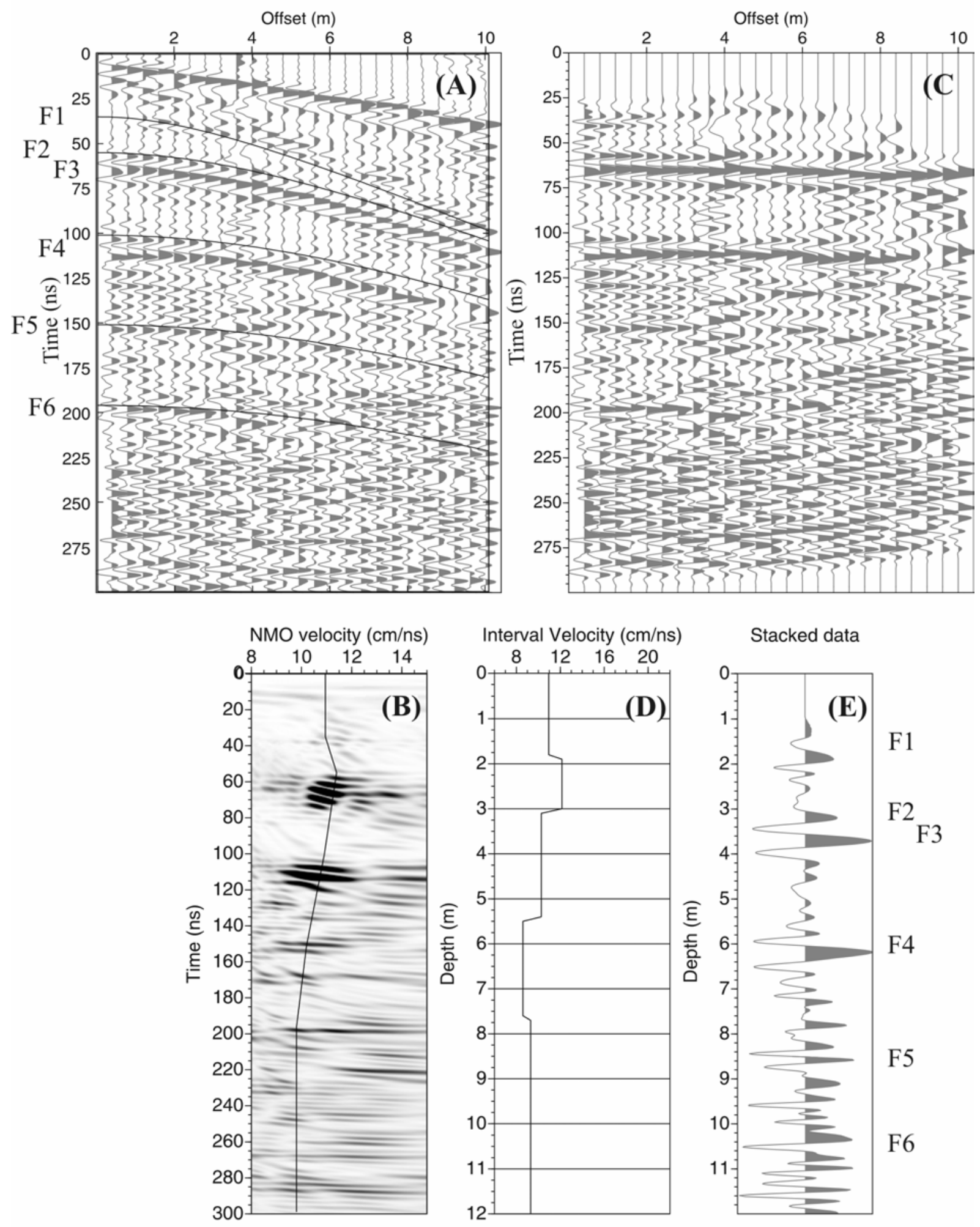

Stacked data

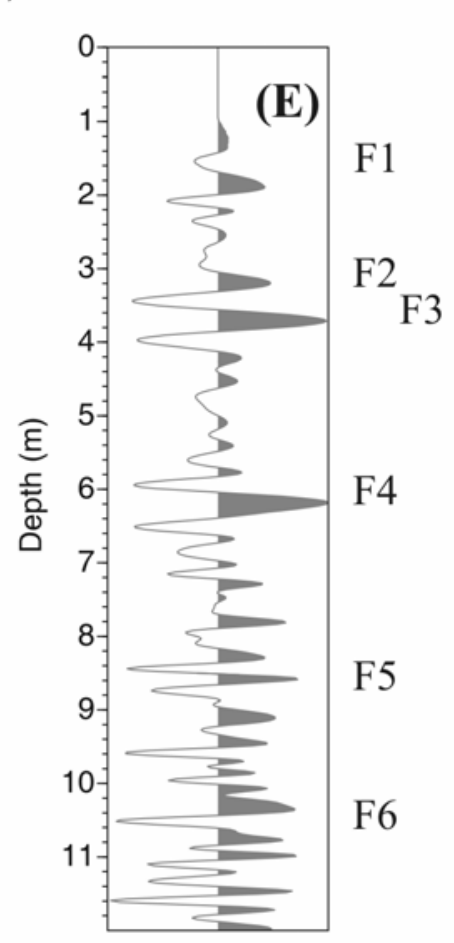

\section{Figure 5}





Figure 6 


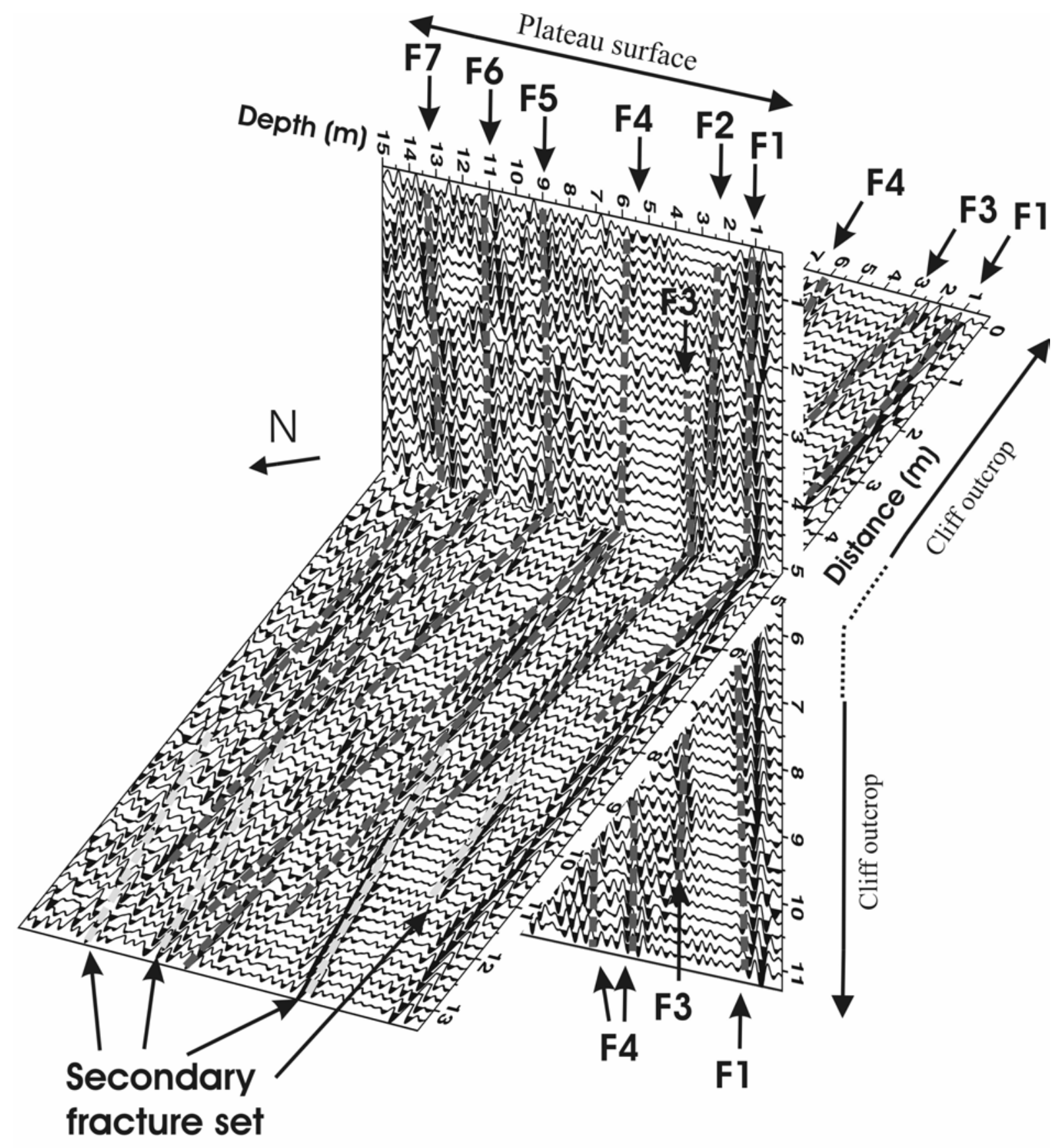

Figure 7 

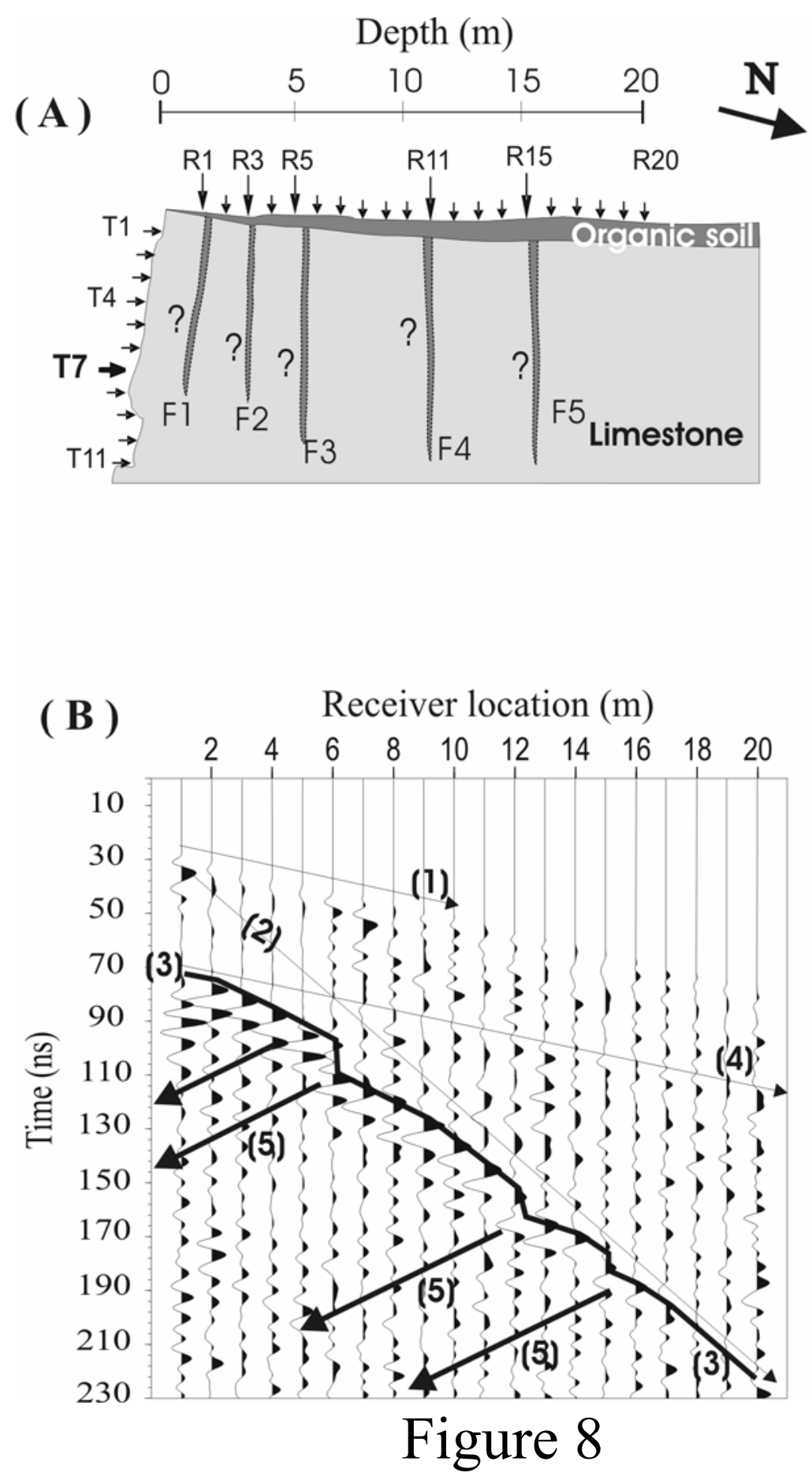

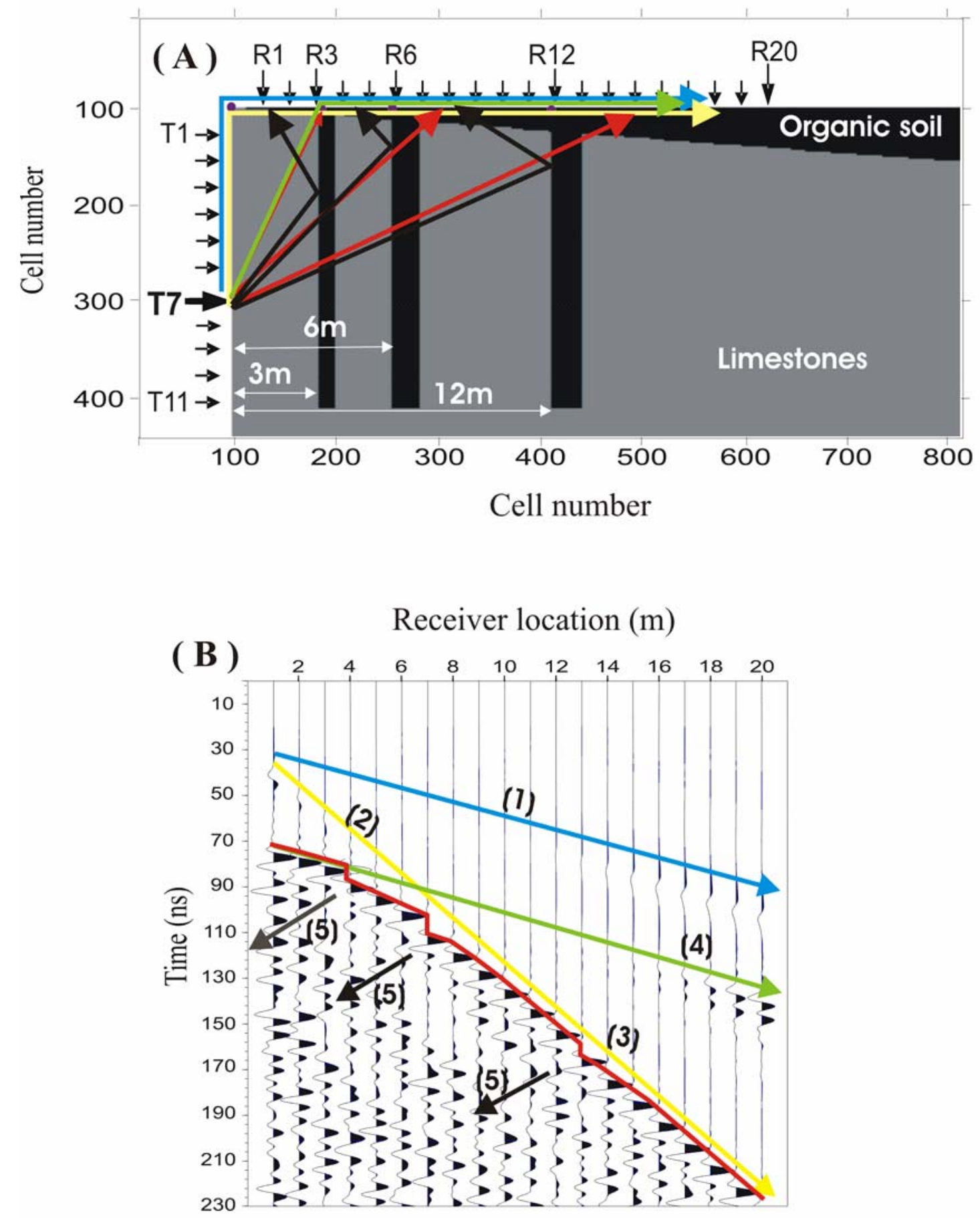

Figure 9 

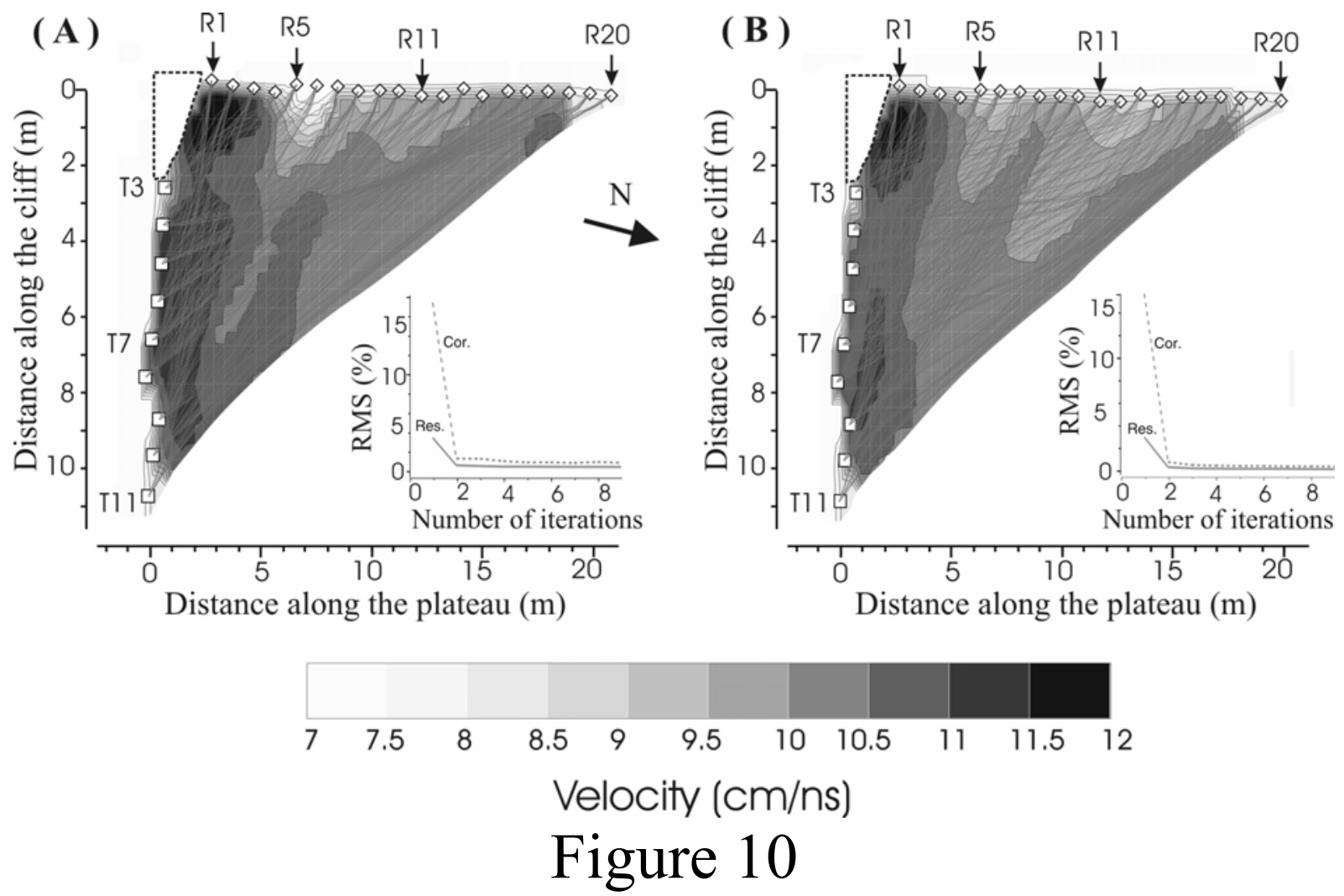